\title{
Molecular identification of Trichomonas tenax in the oral environment of domesticated animals in Poland - potential effects of host diversity for human health
}

\author{
Monika Dybicz ${ }^{1, A-F}$, Konrad Perkowski ${ }^{2, B, C}$, Wanda Baltaza ${ }^{3, B, D}$, Marcin Padzik ${ }^{3, C, E}$, \\ Aleksandra Sędzikowska ${ }^{1, B}$, Lidia Chomicz ${ }^{3, C, E}$ \\ ${ }^{1}$ Department of General Biology and Parasitology, Medical University of Warsaw, Warsaw, Poland \\ ${ }^{2}$ Department of Orthodontics, Medical University of Warsaw, Warsaw, Poland \\ ${ }^{3}$ Department of Medical Biology, Medical University of Warsaw, Warsaw, Poland \\ A - Research concept and design, B - Collection and/or assembly of data, C - Data analysis and interpretation, \\ $D$ - Writing the article, $E$ - Critical revision of the article, $F$ - Final approval of article \\ Dybicz M, Perkowski K, Baltaza W, Padzik M, Sędzikowska A, Chomicz L. Molecular identification of Trichomonas tenax in the oral environment \\ of domesticated animals in Poland - potential effects of host diversity for human health. Ann Agric Environ Med. 2018 ; 25 (3): 464-468. \\ doi: $10.26444 /$ aaem/92309
}

\begin{abstract}
Introduction. The protozoan Trichomonas tenax is considered to be a human specific flagellate of the oral cavity, found in humans with poor oral hygiene and advanced periodontal disease. Morphological variability and great similarity between species occurring in humans and animals, complicate the specific identification of trichomonads, using microscopic examination and other standard parasitological techniques.

Objective. The aim of the study was to search for and identify T. tenax in domesticated animals using molecular methods. The obtained data were assessed in terms of potential effects of a spread of the species deriving from the animals in the human environment.

Materials and method. 301 animals: 142 dogs, 57 cats and 102 horses, were examined in terms of their mouth status and occurrence of trichomonads. ITS1-5.8S rRNA-ITS2 region was amplified and sequenced.

Results. Finally, 7 dogs, 3 cats and 1 horse were diagnosed positive for T. tenax by PCR. In the oral cavity of $9 / 11$ animals, gingivitis and dental plaque accumulation were diagnosed. $9 / 11$ sequences of trichomonad isolates showed $100 \%$ identity with T. tenax sequence derived from the GenBank. The sequences of 2 isolates differed by substitutions.

Conclusions. It was proved that T. tenax, considered so far as a human specific parasite, can also inhabit the oral cavity of dog, cat and horse. To summarize, T. tenax was detected in the mouths of different domesticated animals, indicating that in Poland it can colonize a wider range of hosts than previously known. The owners of 3 dogs showed oral tissue inflammation of different intensity and were also positive for T. tenax; therefore, oral trichomonosis spread from humans to domestic animals and conversely should be taken into consideration.
\end{abstract}

Key words

PCR, specificity, sequencing, Trichomonas tenax, oral trichomonosis, epidemiology, Poland, domesticated animals, humans

\section{INTRODUCTION}

The protozoan Trichomonas tenax is a cosmopolitan flagellate inhabiting the oral cavity of humans with poor oral hygiene and advanced periodontal disease [1]. The trichomonad has also been detected in the oral cavities of patients with decreased immunity due to congenital systemic diseases associated with stomatognathic and smooth-tissue deteriorations, and indicating difficulties in the maintenance of good oral hygiene [2-4]. T. tenax has also been found in other organs and tissues, such as lymph nodes, submaxillary glands, tonsils, bronchi, lungs, mammary gland and liver [5-15]. Some of these cases were older adults or patients with decreased immunity due to tumours or alcoholism. In available world literature, T. tenax is still considered to be a commensal, although high proteolytic, and especially

Address for correspondence: Monika Dybicz, Department of General Biology and Parasitology, Medical Uiversity of Warsaw, Poland

e-mail: mon.tu@gmx.net

Received: 09.05.2018; accepted: 15.06.2018; first published: 12.07.2018 collagenolytic activity of this flagellate accounts for its destructive effect on mucous membranes and tissues. In the cells of T. tenax many proteolytic enzymes affecting pathogenicity have been described [16-21].

Trichomonads have been detected in some primates and dogs [22-24]; however, it remains unclear whether T. tenax is specific only to humans. T. tenax was diagnosed by the authors of the current study and by others in the mouths of dogs and cats by PCR-RFLP analysis [25-27]. As reported earlier, the oral cavity of such domestic animals can be inhabited by 2 trichomonads: Tetratrichomonas canistomae and Tetratrichomonas felistomae [22, 23]. Data from the literature concerning these 2 species are incomplete, although their morphological identity suggests they may be one species. The oral cavity of a horse can be inhabited by Trichomonas equibuccalis [28]. Morphological variability and great similarity of T. canistomae, T. felistomae and T. equibuccalis occurring respectively in dogs, cats and horses, complicate the specific identification using microscopic observation, and a standard parasitological technique. The pathogenicity of 
these species in animals is unclear although the occurrence of trichomonads was observed in dogs diagnosed with tartar and gingivitis. German studies conducted on the trichomonads detected in the oral cavities of dogs, cats and horses, were based on electron microscopy and suggest that these flagellates belong to the genus Trichomonas [29-31], but the characterization of the protozoans was not confirmed by any other method.

Molecular diagnostic techniques have been developed for the detection and identification of Trichomonas species. The amplification of ITS and 5.8S rRNA genes by PCR, followed by sequencing, have been frequently applied and proved to be a reliable tool for rapid and specific characterization of trichomonads [27, 32-36]. The 5.8S rRNA sequences are present in multiple copies in the genome, and are conserved in certain regions and variable in others, even between very closely related species.

\section{OBJECTIVE}

The aim of the study was to identify T. tenax by conducting molecular analysis of trichomonads occurring among mouth microbiota of domesticated animals. Additionally, the obtained data were assessed in terms of potential effects of a zoonotic spread of the species deriving from the animals in the human environment.

\section{MATERIALS AND METHOD}

Materials from animals. A total of 301 animals were examined in terms of their mouth status and occurrence of trichomonads: 142 dogs, aged between 3 months and 14 years, 57 cats aged from 7 months to 15 years, and 102 horses aged from 4 to 20 years. For qualitative research and microorganism species identification, swabs were obtained from each animal by wiping the lower and upper gums with sterile cotton buds previously immersed in PBS. The buds were rinsed with PBS and the received fluid was used for DNA isolation.

DNA extraction. $100 \mu \mathrm{l}$ of the swabs were centrifuged at $5,000 \times \mathrm{g}$ for $10 \mathrm{~min}$. The pellet was washed twice in PBS, centrifuged at $5,000 \times \mathrm{g}$ for $10 \mathrm{~min}$, and pellet was dissolved in $100 \mu \mathrm{l}$ PBS. The genomic DNA was extracted using a NucleoSpin kit (Macherey-Nagel, Düren, Germany), following the manufacturer's instructions.

PCR, RFLP and sequencing conditions. The region of ITS15.8S rRNA-ITS2 of different trichomonad species sequences available in GenBank served for the primer design. The primers T1 (5'-GAGAAGTCGTAACAAGGTAACG-3') and T2 (5'-ATGCTTCAGTTCAGCGGGTCT-3') (ARK Scientific Pte Ltd, Maxwell House, Singapore) were used. PCR reactions were performed in a volume of $50 \mu \mathrm{l}$. Reaction mixture consisted of $1 \mu \mathrm{l}$ DNA, $10 \mathrm{pM}$ of each primer, $0.2 \mathrm{mM}$ of each dNTP, $2.5 \mathrm{mM} \mathrm{MgCl}_{2}$ and $1 \mathrm{U}$ Taq DNA polymerase (Qiagen, Hilden, Germany). PCR was performed in PTC-200 thermal cycler (MJ Research, Waltham, USA) in the following conditions: initial denaturation for $5 \mathrm{~min}$ at $94^{\circ} \mathrm{C} ; 35$ cycles of denaturation for $30 \mathrm{~s}$ at $94^{\circ} \mathrm{C}$, annealing for $30 \mathrm{~s}$ at $60^{\circ} \mathrm{C}$, extension for $45 \mathrm{~s}$ at $72^{\circ} \mathrm{C}$. The PCR products were observed under UV light in $2 \%$ agarose (MetaPhor, FMC BioProducts, Philadelphia, USA), gel stained with ethidium bromide. PCR products were digested with restriction enzyme DdeI. $7 \mu \mathrm{l}$ of the PCR products were added to the reaction mixture: $1 \times$ buffer, $1 \mathrm{u}$ of restriction endonuclease DdeI (Promega, Madison, USA). The final volume was adjusted to $15 \mu \mathrm{l}$ with sterile water. The digestion was carried on at $37^{\circ} \mathrm{C}$ for 2 hours. The fragments were separated on $3 \%$ gel, as above. All PCR products were purified and then directly sequenced in both directions using a BigDye Ready Reaction Cycle Sequencing kit and an ABI 3730 Genetic Analyzer [Applied Biosystems, Foster City, USA]. Chromatograms were manually checked and edited using Chromas 2.0. The obtained sequences were aligned with others retrieved from NCBI GenBank using ClustalW2 [http://www.ebi.ac.uk/Tools/clustalw2].

\section{RESULTS}

Differences in mouth status were expressed regarding periodontal disorders, tartar and stomatitis observed in some analyzed animals. DNA extracted from all samples from dogs, cats and horses were used as the template in separate PCRs to amplify the region of ITS1-5.8S rRNAITS2. The product size was $368 \mathrm{bp}$. Digestion of the PCR products with DdeI endonuclease created 125, 116, 77 and 50 bp fragments (Fig. 1). Eleven samples were diagnosed as positive for T. tenax by amplification of the ITS1-5.8S rRNA-ITS2 region (Table 1). The cases of 7 dogs infected with $T$. tenax, considered $25 \%$ of all infected dogs, were at the age of 5-13 years (average about 10) and the pathological changes in the oral cavity, such as inflammation of gums and tartar, were diagnosed (Tab. 2). Moreover, the owners of these 7 dogs were also investigated and this examination revealed that 3 of the owners (aged of 39-46 years, with some symptoms of oral tissue inflammation) were positive for T. tenax. Three cats infected with T. tenax were aged 1-6 years. The older cats had tartar, but the young cat's oral cavity showed more favourable status (Tab. 2). One horse infected with $T$. tenax was 7 years old with good mouth condition. In the cases of infected cats and horse, T. tenax was the only species detected.

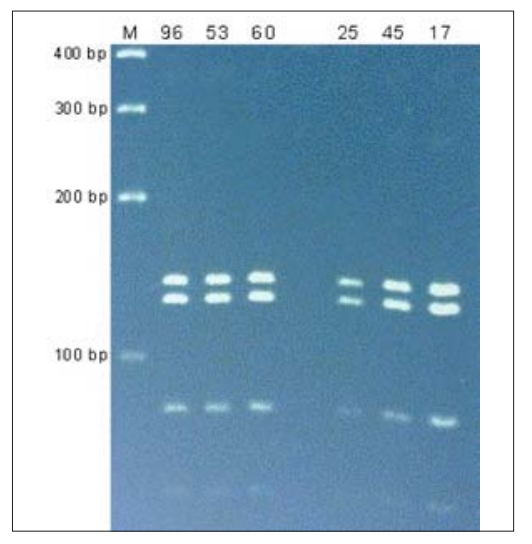

Figure 1. Electrophoresis of restriction fragments obtained by Ddel endonuclease digestion on 3\% agarose (MetaPhor, FMC BioProducts, Philadelphia, USA) gel stained with ethidium bromide.

Abbreviations: M - molecular marker (100 bp DNA Ladder, Promega, Madison, USA); isolates: no. 96 - dog, no. 53 - dog, no. 60 - dog, no. 25 - cat, no. 45 - cat, no. 17 - horse. 
Table 1. Prevalence of T. tenax isolated from the mouths of domesticated animals

\begin{tabular}{lcc}
\hline $\begin{array}{l}\text { Investigated } \\
\text { domesticated animals }\end{array}$ & $\begin{array}{c}\text { No. of animals infected } \\
\text { with T. tenax } \\
\text { / No. of investigated }\end{array}$ & $\begin{array}{c}\text { Prevalence of } \\
\text { animals infected with } \\
\text { the trichomonad }\end{array}$ \\
\hline Dogs & $\mathbf{7 / 1 4 2}$ & $\mathbf{4 . 9 3 \%}$ \\
\hline Cats & $\mathbf{3} / \mathbf{5 7}$ & $\mathbf{5 . 2 6} \%$ \\
\hline Horses & $\mathbf{1 / 1 0 2}$ & $\mathbf{0 . 9 8} \%$ \\
\hline
\end{tabular}

Table 2. Characteristics of investigated animals infected with T. tenax

\begin{tabular}{lccccc}
\hline Animals & $\begin{array}{c}\text { Oral isolate } \\
\text { No.: }\end{array}$ & Gender & $\begin{array}{c}\text { Age } \\
\text { (years) }\end{array}$ & Tartar & $\begin{array}{c}\text { Inflammations } \\
\text { in mouth }\end{array}$ \\
\hline & 11 & Female & 8 & + & + \\
\cline { 2 - 6 } & 46 & Male & 9 & + & + \\
\cline { 2 - 6 } Dogs & 53 & Female & 5 & + & - \\
\cline { 2 - 6 } & 60 & Male & 11 & - & + \\
\hline & 84 & Male & 12 & + & - \\
\hline & 123 & Male & 13 & + & + \\
\hline \multirow{2}{*}{ Cats } & 19 & Memale & 10 & + & - \\
\hline Horse & 25 & Male & 5 & + & - \\
\hline & 45 & Female & 6 & + & - \\
\hline
\end{tabular}

The ITS1-5.8S rRNA-ITS2 region of trichomonad-positive isolates was sequenced and compared with sequences of Trichomonas genotypes available in NCBI GenBank. Nine of 11 sequences showed $100 \%$ identity with $T$. tenax sequence U86615 derived from GenBank. The sequences of 2 isolates differed by substitutions. The observed substitution in dog isolate No. 53 was $\mathrm{T} \rightarrow \mathrm{A}$ in position 60 of ITS1 region. Another substitution in dog isolate No. 96 was $A \rightarrow C$ in position 307 of ITS2 region. All sequences were deposited in GenBank with Accession Nos. KP027402, KP120698KP120707.

\section{DISCUSSION}

According to the available data from the literature on the occurrence of trichomonads in the oral cavity of humans and domesticated animals, it has been claimed, that these protest species are highly specific for their hosts: Trichomonas tenax for humans, Tetratrichomonas canistomae for dogs, Tetratrichomonas felistomae for cats and Trichomonas equibuccalis for horses. In recent years, they were also detected in other hosts. One case concerned the occurrence of T. tenax in monkeys [24]. Within past decades, doubts have arisen about the specificity of these protozoans. Based on microscopic observation, Levine [24] suggested that the T. canistomae and T. felistomae, as well as T. equibuccalis and T. tenax species, might be identical. Several attempts at experimental cross-infections were carried out. The first trial was conducted by Hinshaw [37] who infected dogs with T. tenax 5 times, and assumed that the positive outcome depended on pre-existing gingivitis. Later, Simitch and Kostitch [38] infected human volunteers. Infection of humans by T. tenax was achieved very easily, while the infection of dogs was unsuccessful. Experimental infections with dog- specific T. canistomae succeeded only with 3 adult dogs, but failed with 3 young dogs, a young wolf, and 3 human male volunteers. Simitch [28] infected a donkey successfully with T. equibuccalis, isolated from the horse, but attempts to infect cow, sheep, and goat were unsuccessful [38]. In these experiments, identification of trichomonad species was based on morphological study and cultivation; therefore, according to current diagnostic methods, it is unclear whether the species characterization was appropriate. Also, a group of scientists from Germany showed that microscopic study, even by scanning electron microscope, was not sufficient for differentiation of trichomonad species [29-31]. Basing their work on morphometric measurements of flagellates obtained from 31 dogs [29], 21 cats [30], and 6 horses [31], the authors classified them as belonging to the genus Trichomonas, but the species were not determined.

As identification of trichomonad species by conventional methods encounters difficulties, this indicates that some cases described as trichomonosis caused by Trichomonas tenax or Tetratrichomonas canistomae should be verified. Using molecular techniques T. tenax was diagnosed in the oral cavity of dogs, cats and in the mandibular gland of a $\operatorname{dog}[25-27]$.

T. tenax is still discussed as a commensal organism, although a relationship between the increased occurrence of this protozoan and progression of periodontal disease has been described [1-4]. The high frequency of T. tenax detected in humans with pathological changes in the oral cavity, along with the variability in protein profiling and proteolytic activity supports the pathogenic nature of T. tenax [21, 40].

The authors of the current study previously showed that oral cavity colonization with the trichomonads differed depending on host age, and correlated with symptoms of teeth, periodontium and/or gingival deteriorations noted more frequently in the oldest persons [2-4]. The human oral cavity, as one of the most taxonomically diverse body sites for symbiont colonization, can include various endo- and exogenous species, forming the oral biofilm on surfaces of mucous membranes and teeth. The species are structurally and functionally organized into polymicrobial communities with complex interrelations between particular oral microbiota and host organism. Many biotic and abiotic factors can alter labile oral microbiome homeostasis. The trichomonad infection can be considered as the factor influencing homeostasis of the mouth multispecies community and associated with some pathological changes in the human oral cavity. Moreover, results of TEM studies [3] showed a potential role of the protozoans as sources/vectors of bacterial species - the secondary infection agents transmitted within the T. tenax vacuoles. The prevalence of these protozoans was particularly high in patients with decreased immunity, connected with congenital disease, as well as in those under chronic immunosuppression; thus, an opportunistic nature of the protozoans cannot be excluded.

Recently, Ribeiro et al. conducted studies showing the ability of T. tenax to damage different mammalian cells, and when in contact with target cells in vitro, it behaves similarly to T. vaginalis [21]; therefore, the infection of T. tenax in humans and animals may be the factor inducing or exacerbating inflammation. In the presented study, periodontitis and tartar in dogs infected with T. tenax was observed, similar to the situation described by Hinshaw, who stated that the condition of an effective infection was previous gingivitis 
[37]. However, a young cat and a horse positive for T. tenax did not show any abnormalities in their oral cavity; similarly, oral protozoans are rarely found in children. The presented study revealed that $T$. tenax can inhabit the oral cavity of dog, cat and horse. Even though the number of infected cats and horses was low - only 3 and 1 , respectively, it is significant that T. tenax was the sole species identified in the oral cavity of these animals. Seven dogs were diagnosed to have T. tenax. The owners of these dogs were also investigated, and this examination revealed that 3 of the owners were positive for T. tenax. The infection of this protozoan is spread through saliva, droplet spray and kissing, or on contaminated dishes, glasses and hands.

It has been already reported that $T$. tenax was easily spread between the members of a family [39]; therefore, new data added in the presented study indicates the possibility of a mutual exchange of trichomonads between different species of hosts.

\section{CONCLUSIONS}

This study shows the occurrence of T. tenax in the oral cavities of dog, cat and horse; this species was the only trichomonad identified in these animals investigated by us. The fact that T. tenax was found in animals and their owners may indicate the familial or household character of infections with this species and implies the possibility of oral trichomonosis spread from humans to domesticated animals and vice versa; therefore, trichomonosis of the oral cavity can be considered as an anthropozoonosis or zooanthroponosis.

According to the above findings, T. tenax can inhabit the mouth of different species of domesticated animals. Moreover, the results of this study indicate that the trichomonad species detected in Poland is capable of colonizing a wider range of hosts than was previously known. It also should be emphasized that in the human environment, the oral trichomonosis can spread between domesticated animals and humans. Therefore, the influence of host diversity of this species, and thus potential host origin of this causative agent, should be taken into consideration when assessing the appearance of clinical signs of oral infection by T. tenax. Further in-depth studies are being conducted to help explain such relationships.

\section{REFERENCES}

1. Kurnatowska AJ, Dudko A, Kurnatowski P. Invasion of Trichomonas tenax in patients with periodontal diseases. Wiad Parazytol. 2004; 50: 397-403.

2. Cielecka D, Chomicz L, Piekarczyk J, Walski M, Zawadzki PJ, Bednarczyk A, Szubińska D. Oral cavity condition and occurrence of parasitic protozoans in patients with genetic diseases. Acta Parasitol. 2000; 45(2): 107-112.

3. Chomicz L, Piekarczyk J, Starościak B, Fiedor P, Piekarczyk B, Szubińska D, Zawadzki PJ, Walski M. Comparative studies on the occurrence of protozoans, bacteria and fungi in the oral cavity of patients with systemic disorders. Acta Parasitol. 2002; 47(2): 147-153.

4. Zawadzki PJ, Starościak B, Perkowski K, Baltaza W, Padzik M, Pionkowski K, Chomicz L. Evaluation of selected oral cavity microbiota - risk factors of management complications in patients with masticatory system disorders. Ann Parasitol. 2016; 62(1): 71-76

5. Duboucher $C$, Farto-Bensasson $F$, Chéron $M$, Peltier JY, Beaufils $F$, Périe G. Lymph node infection by Trichomonas tenax: report of a case with co-infection by Mycobacterium tuberculosis. Hum Pathol. 2000; 31: 1317-1321. doi:10.1053/hupa.2000.18502.
6. Duboucher C, Mogenet M, Périé G. Salivary trichomoniasis. A case report of infestation of a submaxillary gland by Trichomonas tenax. Arch Pathol Lab Med. 1991; 119: 277-279.

7. Shiota T, Arizono N, Morimoto N, Shimatsu A, Nakao K. Trichomonas tenax empyema in an immunocompromised patient with advanced cancer. Parasite. 1998; 5: 375-377.

8. Stratakis DF, Lang SM, Eichenlaub S, Löscher T, Stein R, Huber RM. Pulmonary trichomoniasis: diagnosis based on identification of irritation in bronchoalveolar lavage. Pneumologie. 1999; 53: 617-619.

9. Mallat H, Podglajen I, Lavarde V, Mainardi JL, Frappier J, Cornet M. Molecular characterization of Trichomonas tenax causing pulmonary infection. J Clin Microbiol. 2004; 42: 3886-3887. doi: 10.1128/ JCM.42.8.3886-3887.2004.

10. Lewis KL, Doherty DE, Ribes J, Seabolt JP, Bensadoun ES. Empyema caused by Trichomonas. Chest. 2003; 123: 291-292. doi:10.1378/ chest.123.1.291.

11. Mahmoud MS, Rahman GA. Pulmonary trichomoniasis: improved diagnosis by using polymerase chain reaction targeting Trichomonas tenax 18S rRNA gene in sputum specimens. J Egypt Soc Parasitol. 2004; 34: 197-211.

12. Leterrier M, Morio F, Renard BT, Poirier AS, Miegeville $M$, Chambreuil G. Trichomonads in pleural effusion: case report, literature review and utility of PCR for species identification. New Microbiol. 2012; 35: 83-87.

13. Dimasuay KGB, Rivera WL. First report of Trichomonas tenax infections in the Philippines. Parasitol Int. 2014; 63: 400-402. doi: 10.1016/j.parint.2013.12.015.

14. Krvavac S. Trichomoniasis of the breast diseased by fibrocystic mastopathy: pathogenic rather than saprophytic relationship [Trichomonas in fibrocystic mastopathy process]. Med Arch. 1998; 52 143-145

15. Jakobsen EB, Friis-Møller A, Friis J. Trichomonas species in a subhepatic abscess. Eu J Clin Microbiol Infect Dis. 1987; 6: 296-297.

16. Ribaux CL, Couble ML, Magloire H, Herbage D. Degradation of type I collagen by Trichomonas tenax: a biochemical study. J Dent Res. 1981; 60: 1202 .

17. Ribaux CL, Magloire H, Joffre A, Morrier JJ. Immunohistochemical localization of fibronectin-like protein on the cell surface of the oral flagellate Trichomonas tenax. J Biol Buccale. 1983; 11: 41-51.

18. Bózner P, Demeš P. Degradation of collagen types I, III, IV and V by extracellular proteinases of an oral flagellate Trichomonas tenax. Arch Oral Biol. 1991; 36: 765-770.

19. Segovic S, Buntak-Kobler D, Galic N, Katunaric M. Trichomonas tenax proteolytic activity. Coll Antropol. 1998; 22: 45-49.

20. Nagao E, Yamamoto A, Igarashi T, Goto N, Sasa R. Two distinct hemolysins in Trichomonas tenax ATCC 30207. Oral Microbiol Immunol. 2000; 15: 355-359.

21. Ribeiro LC, Santos C, Benchimol M. Is Trichomonas tenax a Parasite or a Commensal? Protist. 2015; 166: 196-210.

22. Hegner R, Ratcliffe $H$. Trichomonads from the vagina of the monkey, from the mouth of the cat and man, and from the intestine of the monkey, opossum and prairie-dog. J Parasitol. 1927; 14:27-35.

23. Hegner R, Ratcliffe H. Trichomonads from the mouth of the dog J Parasitol. 1927; 14: 51-53.

24. Levine ND. Flagellates: The Trichomonads", In Veterinary Protozoology. Iowa State University Press, Iowa, 1985: 59-79.

25. Cielecka D, Borsuk P, Grytner-Zięcina B, Turkowicz M. First detection of Trichomonas tenax in oral cavity of dog and cat by PCR-RFLP. Acta Parasitol. 2000; 45: 350-352.

26. Szczepaniak K, Łojszczyk-Szczepaniak A, Tomczuk K, Skrzypek T, Lisiak B, Abd-Al-Hammza Abbass Z. Canine Trichomonas tenax mandibular gland infestation. Acta Vet Scand. 2016; 58: 15.

27. Kellerová P, Tachezy J. Zoonotic Trichomonas tenax and a new trichomonad species, Trichomonas brixi n. sp., from the oral cavities of dogs and cats. Int J Parasitol. 2017; 47: 247-255.

28. Simitch T. Trichomonas equibuccalis $\mathrm{n}$. $\mathrm{sp}$. parasite de la bouche du cheval et de l'âne. Riv Parassitol. 1939; 3: 23-26.

29. Beelitz P, Schöl H, Gothe R. Trichomonaden-Infektionen der Mundhöhle bei Hunden. Kleintierpraxis. 1992; 37: 281-284.

30. Gothe R, Beelitz P, Schöl H, Beer B. Trichomonaden-Infektionen der Mundhöhle bei Katzen in Süddeutschland. Tierärztl Prax. 1992; 20: 195-198.

31. Schöl H, Beelitz P, Gothe R. Trichomonaden-Infektionen der Mundhöhle bei Pferden in Süddeutschland. Tierärztl Prax. 1992; 20: 608-610.

32. Chakrabarti D, Dame JB, Gutell RR, Yowell CA. Characterization of the rDNA unit and sequence analysis of the small subunit rRNA and 
5.8S rRNA genes from Tritrichomonas foetus. Mol Biochem Parasitol. 1992; 52: 75-83.

33. Gunderson J, Hinkle G, Leipe D, Morrison HG, Stickel SK, Odelson DA, Breznak JA, Nerad TA, Müller M, Sogin ML. Phylogeny of trichomonads inferred from small-subunit rRNA sequences. J Eukaryot Microbiol. 1995; 42: 411-415.

34. Fukura K, Yamamoto A, Hashimoto T, Goto N. Nucleotide sequence of the S rRNA gene and phylogenetic analysis of Trichomonas tenax. Microbiol Immunol. 1996; 40: 183-188.

35. Felleisen RS. Comparative sequence analysis of $5.8 \mathrm{~S}$ rRNA genes and internal transcribed spacer [ITS] regions of trichomonadid protozoa. Parasitology. 1997; 115: 111-119.

36. Walker RL, Hayes DC, Sawyer SJ, Nordhausen RW, Van Hoosear KA, BonDurant RH. Comparison of the 5.8S rRNA gene and internal transcribed spacer regions of trichomonadid protozoa recovered from the bovine preputial cavity. J Vet Diag Invest. 2003; 15: 14-20.

37. Hinshaw HC. Experimental infection of dogs with Entamoeba gingivalis and Trichomonas of human mouth. Proc Soc Exp Biol Med. 1928; 25: 430 .

38. Simitch T, Kostitch D. Présence de Trichomonas canistomae Hegner et Ratcliff chez les chiens de la Serbie du sud. Sa différenciation d'avec Trichomonas elongata Steinberg. Ann Parasitol. 1938; 16: 33-35.

39. Kurnatowska AJ, Dudko A, Turkowicz M. Familial infections with Trichomonas tenax [O.F. Müller, 1773], Dobel, 1939. Wiad Parazytol. 2004; 50: 35-40.

40. El Sibaei MM, Abdel-Fattah NS, Ahmed SA, Abou-Seri HM. Growth kinetics, antigen profiling, and proteinase activity of Egyptian Trichomonas tenax isolates derived from patients having oral infections. Exp Parasitol. 2012; 130: 416-422. doi: 10.1016/j.exppara.2012.01.018. 